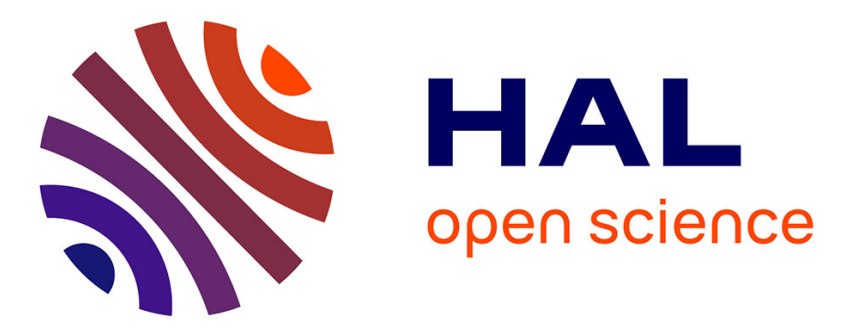

\title{
Costs of managing severe immune thrombocytopenia in adults: a retrospective analysis
}

\author{
Mehdi Khellaf, Jean-Gabriel Le Moine, Priscille Poitrinal, Camille
}

Francesconi, Albert Haddad, Philippe Bierling, Marc Michel, Laurent Eckert, Robert Launois, Bertrand Godeau

\section{To cite this version:}

Mehdi Khellaf, Jean-Gabriel Le Moine, Priscille Poitrinal, Camille Francesconi, Albert Haddad, et al.. Costs of managing severe immune thrombocytopenia in adults: a retrospective analysis. Annals of Hematology, 2010, 90 (4), pp.441-446. 10.1007/s00277-010-1087-x . hal-00583542

\section{HAL Id: hal-00583542 https://hal.science/hal-00583542}

Submitted on 6 Apr 2011

HAL is a multi-disciplinary open access archive for the deposit and dissemination of scientific research documents, whether they are published or not. The documents may come from teaching and research institutions in France or abroad, or from public or private research centers.
L'archive ouverte pluridisciplinaire HAL, est destinée au dépôt et à la diffusion de documents scientifiques de niveau recherche, publiés ou non, émanant des établissements d'enseignement et de recherche français ou étrangers, des laboratoires publics ou privés. 


\section{Costs of Managing Severe Immune Thrombocytopenia in Adults: a Retrospective Analysis}

Mehdi KHELLAF ${ }^{1}$ MD; Laurent ECKERT ${ }^{2}$ PhD; Priscille POITRINAL ${ }^{3}$ MD; Camille FRANCESCONI ${ }^{2}$ MSc; Albert HADDAD ${ }^{3}$ MD; Philippe BIERLING ${ }^{1}$ MD PhD, Marc MICHEL $^{1}$ MD; Lionel RIOU FRANÇA ${ }^{2}$ MSc; Robert LAUNOIS ${ }^{2} \mathrm{PhD}$; Bertrand GODEAU ${ }^{1}$ MD

1. Service de Médecine Interne, Centre Hospitalier Universitaire, Hôpital Henri Mondor, AssistancePublique Hôpitaux de Paris, Université Paris 12, Créteil, France

2. Réseau d'Evaluation en Economie de la Santé - 28, rue d'Assas - 75006 Paris - France

3. AMGEN (Europe) GmbH, Zug, Switzerland

\section{Author for Correspondence:}

Robert LAUNOIS, Ph.D

REES France - 28, rue d'Assas - 75006 Paris - France

launois.rees@wanadoo.fr

Tel: +33144391690

Fax: +33144391692

\section{Disclosure:}

This study was supported by Amgen Inc. 


\section{Abstract}

Objectives: To report resource utilisation and annual cost for chronic immune thrombocytopenia (ITP) patients enrolled consecutively and followed for one year.

Methods: A single-center, single-arm, retrospective, one-year observational cohort study of adult patients with chronic ITP from a French hospital. Healthcare resource utilisation and mean cost per patient (with 95\% confidence intervals) were estimated for the whole group. Patients requiring at least one hospitalisation formed subgroup 1. Patients with the most severe category of disease formed subgroup 2 (defined as hospitalised patients with $\geqq 1$ immunoglobulin (IVIg) infusion [usually reserved for those with bleeding score >8]). Results: Fifty-seven patients (42F/15M) with a mean age of 48 years (SD: 19) at ITP diagnosis were studied. Mean platelet count at diagnosis was $28 \pm 26 \times 10^{9} / \mathrm{L}$. Mean duration of ITP was 3.1 years (SD: 2); 8 patients had undergone splenectomy at baseline. Subgroup 1 included 27 patients who were hospitalised (full hospitalisation, n=23; and/or day hospitalisation, $n=8)$. Of those, 12 patients received at least one IVIg infusion during hospitalisation (subgroup 2). Total mean cost per patient for the one-year study period was $€ 7,293(95 \% \mathrm{CI}=3,369-13,584)$ for the whole group, $€ 15,334(95 \% \mathrm{CI}=7,876-27,459)$ for subgroup 1, and $€ 26,581(95 \% \mathrm{CI}=12,241-50,578)$ for subgroup 2 . IVIg accounted for 33\% of costs for subgroup 1 and up to $43 \%$ of costs for patients with more severe disease (subgroup 2).

Conclusions: Management of adults with chronic ITP is costly in France, especially for patients with severe disease. IVIg use was a major cost driver.

\section{Key words:}

Immune thrombocytopenia; cost of illness; resource utilisation 


\section{Introduction}

Immune thrombocytopenia is a rare blood disorder characterized by a low platelet count and mucocutaneous bleeding [1]. It is often a self-limiting acute disease in children. In contrast, adults frequently experience a chronic form of ITP, defined by duration of more than 12 months.

The management of ITP is designed to minimize bleeding events [1-3]. Corticosteroids are prescribed as the first-line treatment. In patients with a very low platelet count and significant bleeding, intravenous immunoglobulin (IVIg) may be an alternative. Splenectomy is a potentially curative treatment for adults with chronic ITP who fail to respond to first-line treatments [4]. Thombopoietin (TPO) receptor agonists are a class of new drugs for which promising results have been reported and observed in clinical practice. They have provided excellent responses in both splenectomised and non-splenectomised patients [5-8]. Ongoing long-term extension trials suggest that response to TPO-receptor agonists persists beyond 4 years and often allows other ITP therapy to be reduced or discontinued [7]. Cessation of treatment leads to return of thrombocytopenia in most cases. Cytotoxic or other immunosuppressive agents should be reserved for patients with severe disease refractory to first and second line treatment $[2,9]$. Rituximab can be an effective immunosuppressive agent when splenectomy fails and has been proposed as an alternative to splenectomy $[10,11]$, although it is not currently registered for use in ITP.

A limited number of studies have examined the costs associated with ITP. These analyses suggest that the healthcare resource utilisation related to the diagnosis, medical therapy, surgery, and treatment of bleeding complications among ITP patients can be substantial, particularly for refractory patients. The present study evaluates resource utilisation and associated costs in one French hospital in adults with chronic ITP. 


\section{Methods}

\section{Design and setting}

This was a single-centre, single-arm, retrospective observational cohort study of adult patients with chronic ITP. The study was conducted at a national referral centre for ITP in France, namely an internal medicine ward at Henri Mondor hospital (Assistance Publique-Hôpitaux de Paris) which has 898 short-stay hospitalisation beds, and can accommodate 55,000 inpatient and 200,000 outpatient encounters per year.

In France, reference centers were created in 2004 in response to a campaign to raise awareness of rare diseases as a public health priority. Each reference centre is in charge of a rare disease and must maintain a high level of expertise in existing treatments, promote and establish effective new treatments by participating in clinical trials or other research activities, and be the key contact for patients' associations.

The objective of the study was to describe current clinical practice and resource utilisation patterns for patients with chronic ITP. An annual cost per patient was also assessed.

\section{Inclusion criteria}

ITP diagnosis was based on the American Society of Hematology (ASH) guidelines for ITP (1). Patients were included if they had chronic ITP, defined as having a platelet count $<50 \times 10^{9} / \mathrm{L}$ that persisted for more than 12 months [12]. Only patients 18 years of age or older at diagnosis were included. Patients with secondary ITP (i.e., resulting from systemic lupus erythematosus, HIV or HCV infection, and lymphoma) were excluded from the study.

\section{Data collection}

The ethics committee approved the study and the procedures were carried out in accordance with the Helsinki Declaration of 1975. Data were retrospectively collected from the medical records of consecutive adult patients with a diagnosis of ITP, who had a healthcare visit in 2005 or 2006 regardless of their platelet count at the time of enrolment and were followed at 
Henri Mondor Hospital (Mondor) for at least one year. Only patients in whom the diagnosis of ITP was made at Mondor and who were followed regularly at Mondor were included. ITP patients diagnosed elsewhere and referred to Mondor for care were excluded. Each patient was assigned an identification number to ensure confidentiality. The date of the first recorded visit starting in the beginning of 2005 was identified for each patient, and the follow-up period was defined as 365 days following the date of that first visit. An electronic Case Report Form was constructed in EpiData [13] and completed.

Demographic variables collected were age, sex, and platelet count at diagnosis. The following types of visits were recorded: outpatient visits, brief hospitalizations ( $<48$ hours $)$ and full hospitalisations ( $\geq 48$ hours). (NOTE: The common French terminology distinguishes hospitalizations as stays $<48$ hours and hospital stays $\geq 48$ hours.) For full hospitalisations, the length of stay was collected as well as data on those patients who underwent splenectomy. Resource consumption was analysed for the study population and for two subgroups of patients used as proxies for increasing disease severity. Subgroup 1 included patients who were hospitalised at least once during the study period for modification of ITP treatment, side effects due to ITP treatments, or bleeding symptoms related to ITP. We also aimed to assess resource use among the subgroup of hospitalised patients with very severe chronic ITP (subgroup 2). In our institution, patients are treated according to international guidelines [1, 3]; those with very severe chronic ITP are identified by a bleeding score $>8$ and, according to our previously published strategy, they are managed with IVIg in addition to oral steroids [14]. Bleeding scores for individual patients were not available from the chart audit, therefore receipt of IVIg was used to identify the patient group with severest disease. Resource utilisation for a full year (365 days) following the date of the first recorded visit was collected, which represented a sample of patients at various stages of ITP. Costs were estimated from a French public hospital perspective, using tariffs to value health care resources. 


\section{Resource utilisation and costs}

Cumulative costs for the follow-up period were calculated and reported. Costs for brief hospitalisation (<48 hr), full hospitalisation $(\geq 48 \mathrm{hr})$ and splenectomy were determined using the Diagnosis Related Group (DRG) database in France (Programme de Médicalisation des Systèmes d'Information) [15]. This system was designed to classify hospital cases into one of approximately 500 groups expected to have similar hospital resource use, developed for prospective payment to hospitals. DRGs are assigned by a "grouper" program based on ICD diagnoses, procedures, age, sex, discharge status, and the presence of complications or comorbidities. The costs of $€ 691$ and $€ 3,399$ for brief and full hospitalisations, respectively, and $€ 5,850$ for splenectomy were used for this analysis. Outpatient visits were valued based on the Nomenclature for the General Classification of Professional Procedures (Nomenclature générale des actes professionnels; NGAP) at $€ 22$.

Drug dose, dosage form, frequency and duration of administration as well as platelet transfusion during day or full hospitalisation were also recorded and are presented here. While treatments were not specifically associated to costs (because they are included in the valuation of DRGs), the costs of rituximab and IVIg were added. In France, expensive treatments (more than $€ 300$ per day) are excluded from the DRG because their use significantly changes the cost of a hospital stay. The drug costs were obtained from the APHP (Assistance Publique - Hopitaux de Paris; Health and social security services - Paris hospitals) database. The average cost per mg was $€ 2.84$ for rituximab and $€ 0.0359$ for IVIg.

\section{Statistical methods}

Means were calculated for types of visits and treatment, and variations were estimated using standard deviations. The confidence intervals for the cost per patient were determined by 
bootstrapping methods because of the small sample size and because cost data are not normally distributed $[13,16,17]$. All computations were done using the SAS/STAT® software, Version 9 of the SAS System for Windows. Missing data were imputed by the most frequent value. If the stop date of treatment was missing, it was assumed that treatment continued until the next follow-up visit. If the end of treatment value was missing for the last follow-up visit, the end of treatment was imputed to be the end of the year. If intake modalities were missing, they were imputed as the most frequent value observed for that particular treatment. 


\section{Results}

\section{Study Population}

Fifty-seven patients with chronic ITP were followed during the observation period of the study. Their baseline characteristics are presented in Table 1. Mean duration of ITP since diagnosis was $3.1 \pm 2$ years during which $8(14 \%)$ patients underwent splenectomy. Twentyseven patients (47\%) were hospitalised during the study period. These patients were classified as subgroup 1 and represented a group with more severe ITP. Of those hospitalised patients, 12 also received IVIg treatment (and per hospital policy should have had bleeding score >8). They were classified as subgroup 2, the subset with the most severe ITP. Resource utilisation and costs for the whole group and for subgroups 1 and 2 are summarised in Tables 2 and 3 . Thirty-six patients were also prescribed oral corticosteroids during the entire study period. Various immunosuppressive drugs were used in 8 patients including vincristine, vinblastine and cyclophosphamide. Splenectomy was carried out in six of the patients and rituximab treatment was initiated in eight cases during the follow-up period. When not considering severity of the disease (all study patients included), the total cost per patient for the one-year follow-up period was $€ 7,294(95 \% \mathrm{CI}=3,369-13,584)$, with $33 \%$ of those costs attributable to IVIg treatment.

\section{Subgroup 1: Hospitalised patients}

Among the 27 patients in subgroup 1, 23 patients were admitted for $\geq 48$ hours and 8 were admitted for $<48$ hours (Table 2 ). The total cost per patient for the study period was $€ 15,334$ $(95 \% \mathrm{CI}=7,876-27,459)$ (Table 3$)$. Table 3 describes the costs for drugs not included in the DRG (i.e., IVIg and rituximab) since the cost of drugs included in the DRG are implicit in the hospital costs. The acquisition cost for IVIg and rituximab represented $33 \%$ and $14 \%$ of the total cost for these patients, respectively. 
Subgroup 2: Very severe chronic ITP (hospitalised patients with $\geq 1$ IVIg treatment)

Among the 12 patients who were treated with IVIg in the hospital, the mean number of full hospitalisations per patient was $2.9 \pm 3.3$ with an average duration of $20.2 \pm 39.3$ days. The cost per patient per year was $€ 26,581(95 \% \mathrm{CI}=12,241-50,578)$ (Table 3). In subgroup 2 , the acquisition cost for IVIg and rituximab represented $43 \%$ and $9 \%$ of the total cost for patients, respectively. 


\section{Discussion}

Treatment of chronic ITP requires therapies which vary considerably by type, duration, and cost. While resource utilisation and costs associated with the treatment of ITP have not been well studied, one analysis in the United States estimated the annual healthcare expenditure on IVIg therapy in ITP patients to range between $\$ 115$ million and $\$ 693$ million . Based on a nationally representative sample of discharge records from 2003 to 2006, a recent study in the United States showed that ITP patients who were hospitalised had higher costs, longer stays, and more in-hospital deaths on average than all other hospitalised patients combined [18]. It is important to have a better understanding of the cost of standard therapy in adults with ITP, particularly for those patients with more severe disease in order to properly evaluate the value of new therapies. Our study assessed the annual cost in a group of patients with chronic ITP followed in a French reference center. A sub-analysis was also performed in two subgroups of patients with more severe disease using hospitalisation and IVIg as proxies for severity.

In this French study, the results show that chronic ITP is an expensive disease with a mean annual cost per patient of $€ 7,294$ which is similar to the cost of other severe chronic diseases such as diabetes mellitus or heart failure $[19,20]$. However, ITP is a heterogeneous disease and while some patients have low platelet counts and do not manifest symptoms, other patients remain at high risk of bleeding and death, and require multiple therapies, hospitalisation and in some cases, splenectomy [2,9]. Nearly half $(27 / 57=47 \%)$ of the cases studied were admitted at least once to the hospital and $12(21 \%)$ required at least one IVIg infusion during hospitalisation. The mean number of hospitalisations and the mean length of stay were found to be higher in patients requiring IVIg treatment. This may be explained by the fact that at Mondor Hospital IVIg use is reserved for life-threatening situations $[1,3]$ and is administered to ITP patients refractory to steroids and with a high bleeding score [14]. As a result, the cost to treat a severe ITP patient is four times higher than that of treating the 
average chronic ITP patient in our study population, with IVIg being the main cost driver. These high costs are similar to annual costs reported to treat other autoimmune diseases treated with biotherapies such as rheumatoid arthritis [21].

To our knowledge, the study by Ruggeri et al [22] is the only study that has attempted to estimate the cost of therapy in a group of adults with chronic ITP. These authors carried out a study focused on hospital costs, calculated as the reimbursements to the hospital by the Italian Health Service, using DRG tariffs. They studied a group of 152 patients followed in a tertiary medical center. In contrast to our study, they did not examine resource utilisation for outpatients. Although it may be difficult to compare costs in different health care settings, it is interesting to note that the median annual cost of $€ 20,125$ reported by Ruggeri is similar to the costs of therapy in the subgroups of severe patients in our study.

One limitation of our study is the assumption that hospitalisation and IVIg are proxies for severity of disease in chronic ITP patients. It is true that as a referral centre, Mondor is more likely to treat patients with the most severe ITP requiring more care as shown by the high doses of immunoglobulins injected on average, leading to a high cost per consumer. However, to avoid the potential bias in estimating costs, we only included patients with ITP diagnosed and followed at Mondor, excluding ITP patients diagnosed elsewhere and referred to Mondor for further evaluation. In addition, it is important to note that DRG valuation tariffs underestimate the real costs as they are weighted average costs of various cases excluding other expensive medications. As an example, the DRG for splenectomy is associated with a cost of $€ 5,850$, which does not include the cost of IVIg administration that may be required pre-surgically in patients refractory to steroids. The exclusion of IVIg costs may also explain the low cost of splenectomy in France compared to the USA and other European countries. It is also important to note that the cost of IVIg in France is lower than the cost in the USA and other countries in Europe. Another limitation of this study is the assumption that all costs of 
treating ITP for all patients in this study have been captured. On the contrary, some patients may have been treated elsewhere (e.g. outpatient setting,). Since treatment and associated costs for those patients may not have been captured in the patient chart at Mondor hospital, it is likely that we may have underestimated the total cost of treating these transient patients. In addition, we were unable to determine the indirect costs, including time lost from work and societal costs, thereby underestimating the total costs. In a recent study, although the difference did not achieve statistical significance, investigators found that ITP patients missed more work days in the past month than controls (2.16 days/month vs 1.67 days/month) [23].

In conclusion, the management of adults with severe chronic ITP is expensive. Currently, the use of IVIg is a major driver of costs in severe chronic ITP patients. 


\section{Acknowledgements:}

We wish to acknowledge Laetitia Languille, Henri Mondor Hospital, for her help in data registry and Susan Mathias and Kathleen Villa, from Health Outcomes Solutions, for their careful reviewing and editing of this manuscript (with funding from Amgen). 


\section{References}

1. George JN, Woolf SH, Raskob GE, Wasser JS, Aledort LM, Ballem PJ et al (1996) Idiopathic thrombocytopenic purpura: a practice guideline developed by explicit methods for the American Society of Hematology. Blood 88: 3-40

2. Godeau B, Provan D, Bussel,J (2007) Immune thrombocytopenic purpura in adults. Curr Opin Hematol 14: 535-556

3. British Committee for Standards in Haematology General Haematology Task Force (2003) Guidelines for the investigation and management of idiopathic thrombocytopenic purpura in adults, children and in pregnancy. Br J Haematol 120: 574-596

4. Kojouri K, Vesely SK, Terrell DR, George JN (2004) Splenectomy for adult patients with idiopathic thrombocytopenic purpura: a systematic review to assess long-term platelet count responses, prediction of response, and surgical complications. Blood 104: 2623-2634

5. Bussel JB, Kuter DJ, George JN, McMillan R, Aledort LM, Conklin GT et al (2006) AMG 531, a thrombopoiesis-stimulating protein, for chronic ITP. N Engl J Med 355: $1672-1681$

6. Kuter DJ, Bussel JB, Lyons RM, Pullarkat V, Gernsheimer TB, George JN et al (2008) Efficacy of romiplostim in patients with chronic immune thrombocytopenic purpura: a double-blind randomized controlled trial. Lancet 371: 395-403

7. Bussel JB, Kuter DJ, Pullarkat V, Lyons RM, Guo M, Nichol JL (2009) Safety and efficacy of long-term treatment with romiplostim in thrombocytopenic patients with chronic ITP. Blood 113: 2161-2171, Erratum in: Blood. 2009;113: 4822

8. Bussel JB, Provan D, Shamsi T, Cheng G, Psaila B, Kovaleva L et al (2009) Effect of eltrombopag on platelet counts and bleeding during treatment of chronic idiopathic thrombocytopenic purpura: a randomised, double-blind, placebo-controlled trial. Lancet 373: 641-648

9. McMillan R, Durette C (2004) Long-term outcomes in adults with chronic ITP after splenectomy failure. Blood 104: 956-960

10. Arnold DM, Dentali F, Crowther MA, Meyer RM, Cook RJ, Sigouin C et al (2007) Systematic review: efficacy and safety of rituximab for adults with idiopathic thrombocytopenic purpura. Ann Intern Med 146: 25-33

11. Godeau B, Porcher R, Fain O, Lefrère F, Fenaux P, Cheze S et al (2008) Rituximab efficacy and safety in adult splenectomy candidates with chronic immune thrombocytopenic purpura - results of a prospective multicenter phase 2 study. Blood 112: 999-1004

12. Rodeghiero F, Stasi R, Gernsheimer T, Michel M, Provan D, Arnold DM et al (2009) Standardization of terminology, definitions and outcome criteria in immune thrombocytopenic purpura of adults and children: report from an international working group. Blood 113: 2386-2393

13. Lauritsen JM (Ed.) (2000-2008) EpiData Data Entry, Data Management and basic Statistical Analysis System. Odense Denmark, EpiData Association. Available at http://www.epidata.dk. Last accessed July 2010

14. Khellaf M, Michel M, Schaeffer A, Bierling P, Godeau B (2005) Assessment of a therapeutic strategy for adults with severe autoimmune thrombocytopenic purpura based on a bleeding score rather than platelet count. Haematologica 90: 829-832

15. Agence française de sécurité sanitaire des produits de santé. Tarification à l'activité (T2A) et médicaments hors du Groupe Homogène de Séjour (GHS). Available at: http://www.afssaps.fr/Dossiers-thematiques/Tarification-a-l-activite-T2Amedicaments/Accueil-T2A/(offset)/0. Last accessed 01/23/2009

16. Mauskopf J (1998) Prevalence-based economic evaluation. Value Health 1: 251-259 
17. Thompson SG, Barber JA (2000) How should cost data in pragmatic randomised trials be analysed? BMJ 320: 1197-1200

18. Danese MK, Lindquist K, Gleeson M, Deuson R, Mikhael J (2009) Cost and mortality associated with hospitalizations in patients with immune thrombocytopenic purpura. Am J Hematol 84: 631-635

19. Gerdtham UG, Clarke P, Hayes A, Gudbjornsdottir S (2009) Estimating the cost of diabetes mellitus-related events from inpatient admissions in Sweden using administrative hospitalisation data. Pharmacoeconomics 27: 81-90

20. Agvall B, Borgquist L, Foldevi M, Dahlström U (2005) Cost of heart failure in Swedish primary healthcare. Scand J Prim Health Care 23: 227-232

21. Joyce AT, Smith P, Khandker R, Melin JM, Singh A (2009) Hidden cost of rheumatoid arthritis (RA): estimating cost of comorbid cardiovascular disease and depression among patients with RA. J Rheumatol 36: 743-752

22. Ruggeri M, Fortuna SF, Rodeghiero FR (2009) The hospitalization need and cost of adult primary immune thrombocytopenia. Haematologica 94 (Suppl 2): abstract 0230

23. Tarantino M, Mathias SD, Snyder CF, Isitt JJ, Gernsheimer T, Young J (2010) Impact of immune thrombocytopenic purpura on physician visits and workplace productivity. Curr Med Res Opin 26: 319-328 
Table 1. Demographic and Baseline Characteristics

\begin{tabular}{|lccc|}
\hline & All patients & Hospitalised patients \\
\cline { 2 - 4 } & & Subgroup 1 & Subgroup 2 \\
\hline Number of patients & 57 & 27 & 12 \\
\hline Time since ITP diagnosis in years, mean (SD) & $3.1(2)$ & $3.1(2)$ & $2.6(1.2)$ \\
\hline Women, $n(\%)$ & $42(74 \%)$ & $21(78 \%)$ & $0(0 \%)$ \\
\hline Pregnant women, $n(\%)$ & $3(5 \%)$ & $55(15)$ \\
\hline Age at diagnosis, years, mean $(\mathrm{SD})$ & $48(19)$ & $20(18)$ & $17(19)$ \\
\hline Platelet count at diagnosis, $x 10 \% / \mathrm{L}$, mean $(\mathrm{SD})$ & $28(26)$ & $17(63 \%)$ & $9(75 \%)$ \\
\hline Platelet count at enrolment, $<20 \times 10 \% / \mathrm{L}, \mathrm{n}(\%)$ & $29(51 \%)$ & & \\
\hline
\end{tabular}


Table 2. Resource Utilization During One Year

\begin{tabular}{|c|c|c|c|c|c|c|c|c|c|}
\hline \multirow[b]{2}{*}{ Type of resource } & \multicolumn{3}{|c|}{$\begin{array}{c}\text { All patients } \\
\mathrm{N}=57\end{array}$} & \multicolumn{3}{|c|}{$\begin{array}{c}\text { Subgroup } 1-\text { Hospitalization } \\
\qquad \mathrm{N}=27\end{array}$} & \multicolumn{3}{|c|}{$\begin{array}{c}\text { Subgroup } 2-\text { Hosp + IVIg } \\
\mathrm{N}=12\end{array}$} \\
\hline & $\begin{array}{c}\# \\
\text { treat } \\
\text { ed }\end{array}$ & $\begin{array}{c}\text { Overall } \\
\text { duration of tx } \\
\text { per pt in days } \\
\text { Mean (SD) }\end{array}$ & $\begin{array}{l}\text { Cumulative dosage } \\
\text { of tx per pt treated } \\
\text { in mg } \\
\text { Mean (SD) }\end{array}$ & $\begin{array}{c}\# \\
\text { trea } \\
\text { ted }\end{array}$ & $\begin{array}{c}\text { Overall } \\
\text { duration of tx } \\
\text { per pt in days } \\
\text { Mean (SD) }\end{array}$ & $\begin{array}{l}\text { Cumulative dosage } \\
\text { of tx per pt treated } \\
\text { in mg } \\
\text { Mean (SD) }\end{array}$ & $\begin{array}{c}\# \\
\text { trea } \\
\text { ted }\end{array}$ & $\begin{array}{c}\text { Overall } \\
\text { duration of tx } \\
\text { per pt in days } \\
\text { Mean (SD) }\end{array}$ & $\begin{array}{l}\text { Cumulative dosage } \\
\text { of tx per pt treated } \\
\text { in mg } \\
\text { Mean (SD) }\end{array}$ \\
\hline \multicolumn{10}{|l|}{ Drugs not included in DRG } \\
\hline Immunoglobulin & 12 & $4.2(8.8)$ & $320,833(671,720)$ & 12 & $4.2(8.8)$ & $320,833(671,720)$ & 12 & $4.2(8.8)$ & $320,833(671,720)$ \\
\hline Rituximab & 8 & $4.0(1.1)$ & $2,475(803)$ & 8 & $4.0(1.1)$ & $2,475(803)$ & 4 & $4.5(1.0)$ & $2,606(951)$ \\
\hline \multicolumn{10}{|l|}{ Treatments included in DRG* } \\
\hline IV corticosteroids & 3 & 9.0 & $5,250(7,579)$ & 3 & 9.0 & $5,250(7,579)$ & 3 & 9.0 & $5,250(7,579)$ \\
\hline Splenectomy & 6 & $1.0(0.0)$ & -- & 6 & $1.0(0.0)$ & -- & 4 & $1.0(0.0)$ & -- \\
\hline \multirow[t]{2}{*}{ Platelet transfusion } & 2 & $2.0(1.4)$ & -- & 2 & $2.0(1.4)$ & -- & 1 & 3.0 & -- \\
\hline & $\begin{array}{c}\# \\
\text { pts }\end{array}$ & $\begin{array}{l}\text { \# visits per pt } \\
\text { Mean (SD) }\end{array}$ & $\begin{array}{c}\text { LOS per admission } \\
\text { in days } \\
\text { Mean (SD) }\end{array}$ & $\begin{array}{c}\# \\
\text { pts }\end{array}$ & $\begin{array}{l}\text { \# visits per pt } \\
\text { Mean (SD) }\end{array}$ & $\begin{array}{c}\text { LOS per admission } \\
\text { in days } \\
\text { Mean (SD) }\end{array}$ & $\begin{array}{c}\# \\
\text { pts }\end{array}$ & $\begin{array}{l}\text { \# visits per pt } \\
\text { Mean (SD) }\end{array}$ & $\begin{array}{c}\text { LOS per admission } \\
\text { in days } \\
\text { Mean (SD) }\end{array}$ \\
\hline Full hospitalisation ( $\geq 48$ hours) & 23 & $2.1(2.5)$ & $12.3(29.1)$ & 23 & $2.1(2.5)$ & $12.3(29.1)$ & 12 & $2.9(3.3)$ & $20.2(39.3)$ \\
\hline $\begin{array}{l}\text { Brief hospitalisation }(<48 \\
\text { hours) }\end{array}$ & 8 & $3.2(1.6)$ & -- & 8 & $3.5(1.5)$ & -- & 3 & $4.3(2.3)$ & -- \\
\hline Outpatient visit & 56 & $3.9(1.7)$ & -- & 26 & $4.3(1.8)$ & -- & 11 & $4.9(1.4)$ & -- \\
\hline
\end{tabular}

- Treatments included in the DRG were not included since they did not add any costs.

- Abbreviations: LOS: length of stay; pt: patient, tx: treatment. 
Table 3. Costs During One Year

\begin{tabular}{|c|c|c|c|c|c|c|c|c|c|}
\hline \multirow[b]{2}{*}{ Type of resource } & \multicolumn{3}{|c|}{$\begin{array}{c}\text { All patients } \\
\mathrm{N}=57\end{array}$} & \multicolumn{3}{|c|}{$\begin{array}{c}\text { Subgroup } 1-\text { Hospitalization } \\
\qquad \mathrm{N}=27\end{array}$} & \multicolumn{3}{|c|}{$\begin{array}{c}\text { Subgroup } 2-\text { Hosp + IVIg } \\
\text { N }=12\end{array}$} \\
\hline & $\begin{array}{c}\# \\
\text { treated }\end{array}$ & $\begin{array}{c}\text { Cost per } \\
\text { consumer* }(€) \\
\text { Mean }(\mathrm{SD})\end{array}$ & $\begin{array}{c}\text { Cost per } \\
\text { patient }(€) \\
\text { Mean }(S D)\end{array}$ & $\begin{array}{c}\# \\
\text { treated }\end{array}$ & $\begin{array}{c}\text { Cost per } \\
\text { consumer* }(€) \\
\text { Mean }(\mathrm{SD})\end{array}$ & $\begin{array}{c}\text { Cost per } \\
\text { patient }(€) \\
\text { Mean }(\mathrm{SD})\end{array}$ & $\begin{array}{c}\# \\
\text { treated }\end{array}$ & $\begin{array}{c}\text { Cost per } \\
\text { consumer* }(€) \\
\text { Mean }(\mathrm{SD})\end{array}$ & $\begin{array}{c}\text { Cost per } \\
\text { patient }(€) \\
\text { Mean }(\mathrm{SD})\end{array}$ \\
\hline \multicolumn{10}{|l|}{ Drugs not included in DRG } \\
\hline Immunoglobulin & 12 & $\begin{array}{c}11,531 \\
(24,142) \\
\end{array}$ & $2,428(11,704)$ & 12 & $\begin{array}{c}11,531 \\
(24,142) \\
\end{array}$ & $5,125(16,753)$ & 12 & $\begin{array}{c}11,531 \\
(24,142) \\
\end{array}$ & $11,531(24,142)$ \\
\hline Rituximab & 8 & $7,054(2,288)$ & $990(2,601)$ & 8 & $7,054(2,288)$ & $2,090(3,490)$ & 4 & $7,428(2,712)$ & $2,476(3,922)$ \\
\hline \multicolumn{10}{|l|}{ Type of visit } \\
\hline Full hospitalisation & 23 & $8,520(10,110)$ & $3,438(7,612)$ & 23 & $\begin{array}{c}8,520 \\
(10,110) \\
\end{array}$ & $7,258(9,798)$ & 12 & $\begin{array}{c}11,664 \\
(13,259) \\
\end{array}$ & $11,664(13,259)$ \\
\hline Brief hospitalisation & 8 & $2,226(1,134)$ & $352(924)$ & 8 & $2,418(1,044)$ & $716(1,249)$ & 3 & $2,994(1,595)$ & $748(1,515)$ \\
\hline Outpatient visit & 56 & $86(37)$ & $85(39)$ & 26 & $95(39)$ & $91(42)$ & 11 & $108(32)$ & $99(44)$ \\
\hline Total costs & & & $\begin{array}{c}7,294(95 \% \\
\text { CI=3,369- } \\
13,584) \\
\end{array}$ & & & $\begin{array}{c}15,334(95 \% \\
\text { CI }=7,876- \\
27,459) \\
\end{array}$ & & & $\begin{array}{c}26,581(95 \% \\
\text { CI }=12,241- \\
50,578) \\
\end{array}$ \\
\hline
\end{tabular}

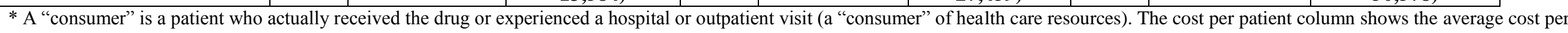
patient for the entire patient population, i.e. counting both patients who use health care resources and those who don't, i.e. "watch and wait" patients 
